\section{Timing of cigarette smoking as a risk factor for multiple sclerosis}

\author{
Jonatan Salzer and Peter Sundström
}

In a recent review evaluating the evidence concerning the association between smoking and multiple sclerosis (MS), the author specifically calls for: (1) studies investigating this association using objective markers for smoking in prospective datasets; and (2) studies addressing the timing of smoke exposure [Wingerchuk, 2012]. We have recently reported the findings of a nested case-control study where levels of cotinine, a recognized biomarker for tobacco use, were measured in biobank blood samples collected median 9 years prior to disease onset [Salzer et al. 2012a]. Elevated levels of cotinine suggestive of smoking $(\geq 10 \mathrm{ng} / \mathrm{ml})$ [Vineis et al. 2005] were associated with a $50 \%$ increased risk of MS when analyzing the entire cohort. When we stratified the cohort according to age at blood sampling, it was evident that it was only among young subjects (below median age at blood sampling, <26.4 years) that this effect was seen. In addition, we used samples collected in the first trimester from 37 pregnant women, whose offspring had later developed MS, and 185 pregnant women whose offspring had not (further described by Salzer and colleagues [Salzer et al. 2012b]) to study the effects of gestational levels of cotinine on the risk of MS in the offspring (previously unpublished data). In this dataset $n=13(35 \%)$ of case mothers and $n=71$ (39\%) of control mothers had cotinine levels $\geq 10 \mathrm{ng} / \mathrm{ml}$. There was no association between elevated cotinine levels during gestation and the risk of MS in the offspring (odds ratio [OR] $0.87,95 \%$ confidence interval [CI] 0.41-1.8, matched logistic regression). In conclusion, our data indicate that smoke exposure during young adulthood is associated with an increased MS risk, but exposure during early gestation according to our limited gestational material, or exposure after the age of 26.4 years is not. This age-of-exposuredependent effect of smoking on MS risk converges with similar findings for other risk factors of MS (vitamin D levels, elevated body mass index [BMI], Epstein-Barr virus [EBV] seroconversion, infectious mononucleosis) suggesting that young adulthood is a crucial time for establishing an individual's risk of the disease [Hedstrom et al. 2012; Munger et al. 2006; Thacker et al. 2006].

\section{Funding}

This study was funded by grants from a regional agreement between Umeå University and Västerbotten County Council on cooperation in the field of Medicine, Odontology, and Health (ALF), The Swedish Association of Neurologically Disabled, The Department of Clinical Neuroscience at Umeå University, Biogen Idec and Merck Serono.

Hedstrom, A., Olsson, T. and Alfredsson, L. (2012) High body mass index before age 20 is associated with increased risk for multiple sclerosis in both men and women. Mult Scler 18: 1334-1336.

Munger, K., Levin, L., Hollis, B., Howard, N. and Ascherio, A. (2006) Serum 25-hydroxyvitamin D levels and risk of multiple sclerosis. $\mathcal{F} A M A$ 296: 2832-2838.

Salzer, J., Hallmans, G., Nystrom, M., Stenlund, H., Wadell, G. and Sundstrom, P. (2012a) Smoking as a risk factor for multiple sclerosis. Mult Scler. Epub ahead of print, DOI: $10.1177 / 1352458512470862$.

Salzer, J., Hallmans, G., Nystrom, M., Stenlund, H., Wadell, G. and Sundstrom, P. (2012b) Vitamin D as a protective factor in multiple sclerosis. Neurology 79: 2140-2145.

Thacker, E., Mirzaei, F. and Ascherio, A. (2006) Infectious mononucleosis and risk for multiple sclerosis: a meta-analysis. Ann Neurol 59: 499-503.

Vineis, P., Airoldi, L., Veglia, F., Olgiati, L., Pastorelli, R., Autrup, H. et al. (2005) Environmental tobacco smoke and risk of respiratory cancer and chronic obstructive pulmonary disease in former smokers and never smokers in the EPIC prospective study. BMF 330: 277.

Wingerchuk, D. (2012) Smoking: effects on multiple sclerosis susceptibility and disease progression. Ther Adv Neurol Disord 5: 13-22.

\section{References}

Ther Adv Neurol Disord

(2013) 6(3) 205

DOI: $10.1177 /$

1756285613479427

(c) The Author(s), 2013. Reprints and permissions: http://www.sagepub.co.uk/ journalsPermissions.nav

Correspondence to: Jonatan Salzer, MD Department of Pharmacology and Clinical Neuroscience, Section of Neurology, Umeå University, Umeå, Sweden jonatan.salzeraneuro. umu.se

Peter Sundström, MD, PhD Department of Pharmacology and Clinical Neuroscience, Section of Neurology, Umeå University, Umeå, Sweden

Visit SAGE journals online http://tan.sagepub.com

@SAGE journals 